\title{
DIÁLOGO Y NOVELA CORTA EN EL SIGLO XVII: LA GUÍA Y AVISOS DE FORASTEROS (1620) DE LIÑÁN Y VERDUGO
}

\author{
DIALOGUE AND THE SHORT NOVEL IN THE \\ $17^{\mathrm{TH}}$ CENTURY: GUÍA Y AVISOS DE FORASTEROS (1620) \\ BY LIÑÁN Y VERDUGO
}

\author{
David GonzÁlez Ramírez \\ Universidad de Jaén \\ david.gonzalez@ujaen.es \\ orcid: 0000-0001-5244-4883
}

\begin{abstract}
RESUMEN: En este trabajo se revisan las definiciones que la crítica ha dado para explicar la Guía y avisos de forasteros (1620) de Liñán y Verdugo y se plantea un análisis a partir de su hibridación formal (diálogo catequístico, narraciones breves enmarcadas a partir del recurso de la sobremesa) y temática apicarada (por cuanto se tratan los peligros que representan en la corte los maleantes, pedigüeños, pícaras, etc.). Además, se pone en relación con otras obras coetáneas para entender mejor su constitución como colección de relatos.
\end{abstract}

Palabras clave: Liñán y Verdugo; Guía y avisos de forasteros; diálogo; novela corta; siglo XvII.

ABSTRACT: This article offers a revision of the different ways that critics have presented Liñán y Verdugo's Guía y avisos de forasteros (1620). An analysis is offered based on the text's hybrid form (dialogue, brief narratives set within the frame-work of post-prandial conversation) and its picaresque content (the dangers that the rogues, beggars and hussies, etc., represent in court). This article also relates the work to other contemporary texts in an effort to better understand its constitution as a collection of stories.

Keywords: Liñán y Verdugo; Guía y avisos de forasteros; dialogue; short novel; $17^{\text {th }}$ century.

Recepción: $1^{\circ}$ de agosto de 2019; aceptación: 2 de diciembre de 2019. 
Cuando la crítica tiene que asumir la responsabilidad de encuadrar ciertas obras narrativas del siglo XviI que colindan con varios géneros, a menudo tropieza con escollos difíciles de solventar; la característica principal en esta época -y no sólo de la prosa- es el hibridismo, con lo que acertar con una propuesta definitoria es a menudo simplificar el hecho literario y limitar el valor estético que presenta la obra. Cuando un texto picaresco se ha vertido en un molde dialogal (Coloquio de los perros de Cervantes, Alonso, mozo de muchos amos de Alcalá Yáñez) o se emparenta con el relato de peregrinación (Tercera parte del Guzmán de Alfarache de Machado y Silva); cuando la literatura de peregrinación penetra en el ámbito de la alegoría (El criticón de Gracián) o cuando la novela corta -o cortesana, al decir de Amezúa (1929) - fluctúa con la pastoril (La Cintia de Aranjuez de Corral), con las narraciones extensas (El forastero de Arnal de Bolea) o con la miscelánea (El filósofo del aldea de Mateo Velázquez), la crítica no puede explicar una obra atendiendo a las dimensiones constitutivas que revela un solo género, sino que es imprescindible bordear otros terrenos para entender la plurivalencia que atesora el texto. Aun tomando como punto de partida el eje vertebrador (colección de novelas, peregrinación, pícaros...) que presente la obra, mirar hacia otros polos es siempre tarea obligada para justipreciar todo el espacio literario que pueda abarcar*.

La Guía y avisos de forasteros, adonde se les enseña a huir de los peligros que hay en la vida de corte y, debajo de novelas morales y ejemplares escarmientos, se les avisa y advierte de cómo acudirán a sus negocios cuerdamente (Madrid, 1620), de Liñán y Verdugo, ha sido desde hace décadas definida con marbetes en ocasiones farragosos y poco aclarativos. En la colección de Liñán y Verdugo confluyen, en una rica contextura de tejidos literarios, la tradición dialógica en su unión con la narrativa breve, siguiendo el modelo de las colecciones enmarcadas que comenzaba a emerger en las primeras décadas del nuevo siglo tras la traducción

"Este trabajo se adscribe al proyecto "La poesía hispano-portuguesa de los siglos XVI y XVII: contactos, confluencias, recepción" (I+D+i. FFI201570917-P; financiado por AEI [Agencia Estatal de Investigación, España] / FEDER, UE), dirigido por S. Pérez-Abadín Barro (USC), y a las líneas del Equipo de Investigación EI_HUM6_2019. Una primera versión de este artículo ha sido leída por R. Malpartida, cuyas pertinentes observaciones han contribuido a mejorarlo. 
y publicación del Decameron en el siglo xv y la divulgación de algunos novellieri (Straparola, Bandello o Cinthio) al español en el último cuarto del xvi. Además, la parte considerada propiamente como narrativa -cuentos, facecias y novelas- se vincula con la temática apicarada y hampesca, pues se trata de poner ejemplos en forma de escarmientos para que el nuevo cortesano que llegaba a pretender o a pleitear no se dejase embaucar por la turbamulta de gorrones y oportunistas que vivían en la corte. Liñán y Verdugo aprovechó parcialmente el molde del diálogo indirecto para enriquecer la conversación de sobremesa con comentarios, anécdotas y aclaraciones al hilo de los temas que se iban tratando.

ENTRE EL COSTUMBRISMO, EL DIÁLOGO, LA MISCELÁNEA Y LA NOVELA CORTA

Esta mixtificación ha llevado a la crítica a sopesar diferentes enmarques genéricos. Correa Calderón (1964, p. xii) le concedió a la Guía ser "la primera muestra del costumbrismo -hecha con la decidida intención de crear un nuevo género, en el que predominase lo descriptivo-, y en la que se advierte al forastero de los peligros de la Corte". A su juicio, el costumbrismo surgió en el siglo XVII, "referido al ambiente de Madrid de modo casi exclusivo, como una consecuencia de la desintegración de la novela, especialmente en su modalidad picaresca y cortesana, con la que se entreveran ciertas obras extravagantes de genio realista" (1964, p. xxiv) ${ }^{1}$. Algunos años antes, González de Amezúa (1951 [1929], p. 198) incidió en que la novela cortesana -es decir, la novela corta- era una rama de la novela de costumbres. Formichi (1976, p. 78), siguiendo la lectura de Correa Calderón, vinculó el costumbrismo con la picaresca:

Più che di novelle si tratta, credo, di quadri di costume: l'azione del racconto è di per sé non molto importante e spesso mutuata da altri scrittori o dai clichés tradizionali senza un vivo interesse dell'autore. Questo si accende invece nelle descrizioni di personaggi, di scene tipiche e colorite, le stesse che appaiono spesso

${ }^{1}$ Este trabajo de Correa CAlderón, publicado como introducción a su selección de textos costumbristas, es la revisión y ampliación de otro redactado un poco antes (1949). Ya SARRAilh (1919) entendió el texto como un documento fiel de la sociedad cortesana. 
nel dialogo vero e proprio e che fanno di questo e della parte narrativa un tutto unitario ed omogeneo di quadri di costume picaresco-cortigiani, di quella particolare, mista qualità tipica della narrativa seiscentesca.

Se pronunció en la misma línea Fernández (1983), quien, a propósito de la temática que trató Liñán y Verdugo, consideró que el tono predominante en la obra es el picaresco, "pero la estructura de la materia indica, además, un influjo visible de las comedias de enredo. Picaresca y comedia estaban enraizadas en lo costumbrista. La Guía es, en superficie y sobre ese fondo, una descripción de las costumbres del Madrid de 1620" (p. 179). Según este crítico -y asumiendo las razones de Gili Gaya (1953)-, Liñán eligió "la fórmula propia de la picaresca degenerada" (p. 183).

No creo que la Guía y avisos de forasteros pueda entenderse como una novela de costumbres y aún menos que el componente descriptivo sea el que domine el espacio narrativo. Salvo algunas pinceladas (no más de las que contenían las novelas de Zayas, Castillo Solórzano o Lope, por ejemplo) en las que se descubrían algunas costumbres de la época, la obra tiene un fin muy determinado: advertirle al forastero los peligros que representa en la corte la gente de mal vivir. En este orden, me parece muy acertado el juicio de Rioja Murga (1993, p. 136), para quien

es preciso hilar muy fino si no queremos incurrir en el error de etiquetar como costumbrista toda novela que recoja, con mayor o menor exactitud, ciertos usos y costumbres de la época. Obviamente, no hace falta decir que cuadros costumbristas podemos encontrarlos, por ejemplo, a lo largo y ancho de la producción picaresca y cervantina, pero claro está que en estos casos la función desempeñada por dichos cuadros queda limitada a la "coloración" del universo novelesco en el que se desarrolla la historia; de tal modo, que ni son independientes de ella ni tienen función per se, requisitos ambos imprescindibles en la más pura ortodoxia costumbrista.

Sobre la vinculación tan recurrente entre Liñán y Zabaleta me pronuncié hace algunos años (González Ramírez 2010a), considerando que la colección de Liñán abre una vía -la novela al servicio de la nueva realidad social de la corte en el siglo XVII- que fue en parte imitada por Castillo Solórzano en Las 
harpias en Madrid (1631), de donde Remiro de Navarra tomó algunas ideas para Los peligros de Madrid (1646), obra clave en el aspecto formal que le facilitó a Zabaleta el patrón compositivo para sus días de fiesta (1654 y 1660). Las dos últimas pueden considerarse como iniciadoras del costumbrismo, en la medida en que lo descriptivo ejerce un papel preponderante, pero no así las primeras, donde hay una acción narrativa que permite hilvanar novelas y cuentos.

Por lo demás, y a propósito de la denuncia social que hay en el texto, entiendo que la Guía y avisos de forasteros contiene un claro mensaje reformista (Maravall 1986; González Ramírez 2010a), en alianza con las enmiendas que proponían arbitristas de la época como Bartolomé Leonardo de Argensola, Pedro de Valencia o Pedro Fernández Navarrete. En este orden de cosas, creo que hay un cambio de paradigma en la literatura anticortesana desde el siglo Xvi (Guevara, Castillejo) hasta el XvII (Salas Barbadillo, Liñán y Verdugo); el punto de inflexión viene marcado por la decisión de Felipe II de establecer la corte definitivamente en Madrid (aunque sabemos que su hijo, Felipe III, la trasladó unos años a Valladolid entre 1601 y 1606) y la llegada masiva de forasteros que pretendían un cargo o prebenda. Por tanto, el leitmotiv de la Guía y avisos de forasteros parte de un tópico literario (la corte como peligro), redimensionado por la nueva circunstancia social y centrado ahora en la gente de mal vivir (maleantes, embusteros, pedigüeños, pícaras, etc.), y no en los aspirantes a palacio.

Otros estudiosos han intentado encorsetar este texto entre los diálogos denominados "misceláneos". Joset (1977, p. xxix), en la introducción a su edición de El viaje entretenido, fue el primero que entendió la Guía y avisos de forasteros como una "miscelánea dialogada" y la emparentó con El pasajero de Suárez de Figueroa; se trataba de una tipología inaugurada -a su entender (1977, p. li) - por El viaje entretenido de Agustín de Rojas, "representante eximio" de esta serie de obras. Tal denominación entra en colisión con la que se viene empleando -alternada también en ocasiones por los mismos especialistas en el diálogo renacentista con el sintagma "diálogo misceláneo"- para aludir a obras como el Jardín de flores curiosas de Antonio de Torquemada o la Agricultura cristiana de Juan de Pineda ${ }^{2}$. Estas dos obras citadas

2 Véase en el preámbulo de Malpartida Tirado (2005, pp. 105-121) a su colectánea Varia lección de plática áurea el apartado en que trata sobre el 
son rigurosamente diálogos directos, lo que las distancia, compositivamente, del texto de Liñán.

Para Auladell (1991, pp. 267-268), quien sigue la definición que aportara Joset, la Guía posee "elementos propios de tratado moralista, de miscelánea, de novela, de obra arbitrista, de «cuadro de costumbres» y hasta de picaresca". Por si fuese poco, el título del libro le llevó a considerar que podía encuadrarse además dentro del género de los avisos -opinión ya emitida por Sánchez Alonso (1925)-, que desde fines del siglo XVI conoció un importante auge. Finalmente, Auladell propuso una denominación heteróclita para definir el género de la Guía: "miscelánea moralizante en forma dialogada" (p. 297). La miscelánea, si atendemos al modelo paradigmático de la Silva de varia lección de Pedro Mejía, se define por su naturaleza enciclopédica, por su desorden compositivo y por su pretensión de aglutinar una suma de materias variadas y una enriquecedora pluralidad temática; este tipo de obras, de ascendencia grecolatina, se destinaba a un nuevo público que a su modo había sido creado por la imprenta y que mostraba más interés por panoramas generales que por obras específicas ${ }^{3}$.

En el siglo XVII apenas quedan obras de este carácter; algunos investigadores han empleado el término miscelánea, aunque con una significación distinta, para referirse a textos como $L a$ Filomena (1621) y La Circe (1624) de Lope de Vega, Los cigarrales de Toledo (1624) de Tirso de Molina o Rimas y prosas (1627) de Bocángel y Unzueta, en los que se amalgama prosa, verso y teatro. Desde hace algunos años, Bradbury (2014 y 2017), con criterios más rigurosos, viene trabajando en la pervivencia de aquellas obras que tratan de divulgar temas de erudición, como las Noches de invierno (1609) de Eslava, El pasajero (1617) de Suárez de Figueroa, El filósofo del aldea (1625), el Para todos (1632) de Montalbán ${ }^{4}$; cada una con su forma idiosincrática, son obras

“diálogo misceláneo"; ahí plantea las dificultades taxonómicas que se derivan de la utilización de este marbete. Contienen especial interés las páginas en las que discute la acuñación de Jacques Joset de "miscelánea dialogada" para referirse a obras tan disímiles como El viaje entretenido de Rojas Villandrando, El pasajero de Suárez de Figueroa y la Guía de Liñán (pp. 122-125).

3 Téngase también en cuenta el valioso artículo de MALPARTIDA Tirado (2007), en el que esboza "una serie de convergencias y divergencias entre formas textuales que de un modo u otro se emparentan con el corpus de las misceláneas" (p. 41).

${ }^{4}$ Es preciso ahora acudir a su edición de VeLÁzQuez (2019 [1625]), en cuya introducción sintetiza los aspectos más relevantes en torno a este asunto. 
vinculadas por la divulgación de temas diversos y constituyen en efecto la herencia de las misceláneas clásicas. Por estas razones, conviene desechar de entrada, para evitar confusiones terminológicas, la voz miscelánea para referirse a la obra de Liñán, en la que no hay voluntad de transmisión de saberes y, además, la conversación entre los cuatro contertulios está orientada en un mismo sentido: amonestar a don Diego, con avisos y narraciones, para que no caiga en los peligros de la corte ${ }^{5}$.

En el entorno de estas definiciones, hace unos años Arredondo dedicó un par de artículos a la obra de Liñán y reconocía que es un texto sugestivo "por hallarse en la encrucijada de un género que decae, la picaresca, del que conserva abundantes rastros; de otro anterior, la colección de novelas enmarcadas en el curso de un diálogo de sobremesa; y de un propósito aleccionador que se plasma en la palabra «escarmiento»" (2001, p. 19). A su juicio, la Guía era una muestra "del modelo picaresco innovado", que se fundamenta en "un diálogo extenso $\mathrm{y}$ variado ilustrado con novelas, que conservan tipos, ambientes, temas y el propósito aleccionador de la picaresca”, pero el componente dialogal está "tan hipertrofiado que, en los años siguientes, terminará por anular la narración” (pp. 20-21). En un trabajo posterior se refirió, con bastante acierto, a la "finalidad exclusivamente funcional y dependiente del marco" de las narraciones, cuyo desenlace trágico ya conocemos de antemano, por lo que se pierde la "capacidad de admirar a los lectores" (2004, pp. 68-69). Insistiendo en esta idea, Arredondo señaló que el autor estaría "mucho más preocupado por explicitar con nitidez su mensaje aleccionador; de ahí que el autor y los respectivos narradores se esmeren en la narración y en la descripción, en detrimento del diálogo entre personajes" (p. 69).

En sus opiniones sobre la marca del diálogo en la obra, resuena la idea de Fernández Nieto (1973), para quien "los per-

5 A propósito de la moralidad, señalada por Auladell, creo que no es necesario insistir en que los autores áureos que ensayaron con fórmulas próximas a la novela manifestaron de forma expresa su voluntad de construir obras ejemplares -Boccaccio ya lo hizo en su Decameron-, aunque en muchos casos, realmente, sus libros se quedasen en los márgenes de lo recreativo. En el caso de la Guía, Liñán manifestó en varias ocasiones que ofrecía al forastero una "guía cristiana" (LiÑán 2011 [1620], p. 174) para que cumpla "con sus obligaciones, no saliendo de los límites de buen cortesano y haciendo como buen cristiano" (p. 307). Esa pátina moralizante -aunque en muchas ocasiones no pasase de un efecto retórico- no es ajena a la mayoría de las obras en prosa del Siglo de Oro. 
sonajes de la introducción no son más que un pretexto para ir engarzando los relatos -novelas cortas con intención doctrinal y didáctica-, manteniéndose su estructura totalmente abierta" (p. 425). Trataré en este trabajo de analizar el componente dialogal para notar cómo la obra de Liñán presenta una variedad de matices que la distancia del modelo de relato enmarcado que se afianzaría en el siglo XVII, cuando se fija una estructura rígida entre la cornice y la narración. Por lo demás, se me antoja muy difícil aceptar que los cuatro dialogantes sean mero recurso para unir las novelas. El fin último de la obra de Liñán es guiar al forastero, y nada mejor que mostrarle los desvaríos de la corte por medio de tres cortesanos con experiencia; además de darle mayor dinamismo, conseguía con tres interlocutores persuadir de forma más contundente al recién llegado a la corte. De otra forma, la obra hubiese sido un conjunto de avisos, acercándose así más al tratado; además, entre los personajes surgen disputas e interrupciones, lo que favorece una enriquecedora recreación dialogal que permite no interpretar la obra como una sucesión de novelas hilvanadas por cuatro personajes acartonados y sin vida ${ }^{6}$.

Este elenco de opiniones da cuenta de que cuando algunos críticos han tratado la cuestión del enmarque genérico del texto de Liñán, las interpretaciones han caminado por senderos con constantes bifurcaciones. Desde la forma estructural en la que se sostiene la categoría "novela corta", con la que se han referido a la Guía y avisos de forasteros (bajo el enmarque de una sobremesa), hasta la que se fundamenta en el contenido de la obra, vista como un libro que se amolda a una fórmula de la picaresca -bien en su fase de descomposición (Gili Gaya 1953 y Fernández 1983), bien como modelo innovador (Arredondo 2001)-, las denominaciones para encorsetar el libro de avisos de Liñán y Verdugo han sido, por la falta de precisión en determinados casos, no demasiado afortunadas. El requerido análisis de la obra de Liñán no puede de ningún modo hurtarse a un justo encuadre en las corrientes narrativas de su época, pero tampoco ha de privilegiarse la forma sobre el contenido o viceversa.

${ }^{6}$ Hace unos años, Fernández Nieto (2013) volvió sobre la Guía y avisos de forasteros, reescribiendo algunas ideas de su artículo citado (1973), a las que añadió algunos apuntes para fundamentar las relaciones entre la obra de Liñán y El Filósofo del aldea de Baltasar Mateo Velázquez. 
Entiendo que un estudio riguroso de la Guía ha de contemplar en igual grado la dilatada plurivalencia genérica del texto, sin sancionar la morfología en virtud de la intención o el sentido. Parte de la crítica, cuando no ha intentado excusar esta labor acudiendo a ineficaces marbetes prefabricados, ha soslayado la cuestión transformando por arte de birlibirloque un texto literario en un manual idiosincrático del pueblo español; se ha pretendido además convertir la obra en un ilusorio minero de datos sobre la vida y costumbres, cuando no hay más que retazos muy concretos sobre estos aspectos sociológicos. Es por ello por lo que no ha pasado de tener generalmente un carácter subsidiario; a esta función auxiliar la han sometido muchos estudiosos al escoliar textos coetáneos, empleándola como documento para fundamentar históricamente sus ediciones.

El género de la Guía y avisos de forasteros debe ser replanteado, teniendo en consideración naturalmente el hibridismo que recorre casi toda la narrativa del siglo XvII, pero desde luego, como antes explicaba, transitando otros contornos. Habrá que examinar con cierta minuciosidad, por un lado, la confluencia de elementos compositivos que centraliza el texto, descartando la catalogación de la obra como una novela picaresca epigonal; es asumible que el autor trató con una materia más o menos próxima a la picaresca, pero la estructuración final alcanzó un resultado muy diferente a este género. Tampoco puede admitirse, por los argumentos ya presentados, la designación que corre últimamente por estudios y trabajos que define la obra de Liñán como una "miscelánea dialogada". Por otro lado, habrá que atender con rigor a la vertiente dialogística que penetra en la obra, examinando la pertinencia del marco boccacciano, analizando los recursos característicos que otorgan sentido a este género, observando la caracterización de los platicantes y examinando la recreación conversacional. Las siguientes páginas tratarán de iluminar estos aspectos de la obra.

\section{DiÁlOGO Y NOVELA EN EL SIGLO XVII}

Las primeras obras del siglo XviI que son referente para la novela corta experimentaron con la forma dialogal, bien como diálogos miméticos o dramáticos -también denominados directos-, en los que se reproducen textualmente las voces de los interlocutores, sin aparecer marca interlocutiva alguna; bien 
como diegéticos o narrativos -llamados igualmente indirectos-, donde se refleja, mediante la modalidad narrativa y el uso de los verba dicendi, la conversación que sostienen, durante un tiempo determinado y un lugar preciso, varios contertulios ${ }^{7}$. Diálogo y novela corta se dan la mano en muchas de las colecciones del siglo XVII. Entre los primeros destacan las Noches de invierno (1609) de Antonio de Eslava, en la que se configura una reunión nocturna entre cuatro hombres, al modo de las Noches áticas de Gelio, para sobrellevar mejor el frío, divulgar conocimientos eruditos y contar novelas; o el Coloquio de los perros (1613) de Cervantes, un diálogo directo que se inserta en la tradición lucianesca -titulado, por cierto, Novela y coloquio que pasó entre Cipión y Berganza, lo cual daba a entender que fundía dos géneros de larga tradición ${ }^{8}$.

En el segundo grupo están Corrección de vicios (1615) de Salas Barbadillo, en la que un personaje, homónimo del autor, cuenta por escrito a su destinataria -y dedicataria del textolas conversaciones que mantuvo con loco-cuerdo, Boca de todas verdades, y las novelas que éste le relató -a excepción de una, compuesta por el narrador-; El pasajero (1617) de Suárez de Figueroa, en el que cuatro personajes narrarán sus experiencias -y con ellas pasarán revista a numerosos asuntos-, a cuyo propósito se intercalará un relato que tiene trazas de novela corta en el alivio VIII; y la Guía y avisos de forasteros de Liñán. Y esto sólo por contar las obras que tienen unos vínculos innegables con la novela corta, porque si ampliamos el género y miramos hacia la narración breve en su sentido lato, podríamos también tratar, por ejemplo, de los Diálogos de apacible entretenimiento (ca. 1605) de Lucas de Hidalgo.

En la Guía y avisos de forasteros de Liñán y Verdugo, tres interlocutores -cortesanos antiguos, pero ninguno de ellos oriundo de la corte, es decir, todos escarmentados en la batalla contra los peligros que entraña la ciudad-se reúnen en una casa para disfrutar de una frugal comida y aprovechar después el espacio

7 Véase Bobes Naves (1992), especialmente el bloque titulado "Pragmática del diálogo" (pp. 33-94). Además, sobre el número de interlocutores en los diálogos, es preciso indicar que solía frecuentemente variar entre dos y cuatro; al igual que en la Guía y avisos de forasteros, en las Noches de invierno, en El pasajero o en la Parte primera de varias aplicaciones y transformaciones (1613) de Rosel y Fuenllana los interlocutores son cuatro.

${ }^{8}$ Sobre el juego de equilibrios entre novela y coloquio en esta obra, véase el excelente y completo estudio de Ruiz Pérez (2008). 
de la tarde, donde, como antes he advertido, ofrecerán avisos y relatarán ejemplos en forma de novelas a un recién llegado al que van a aleccionar ${ }^{9}$. Este marco que potencia el diálogo - proveniente de los modelos italianistas ${ }^{10}$ - se cultivó en España y se adhirió al modelo de novela corta, impulsado durante las primeras décadas del siglo XVII. Al diecisiete llegó el vendaval del diálogo amainando, pero aún hubo autores que se atrevieron a trabajar con él y a sacarle partido ${ }^{11}$.

Si durante el siglo XVI los géneros prosísticos mayores estaban más o menos diferenciados (epístolas, libros de caballerías, de pastores, de pícaros, etc.), es un hecho constatado que el cuento, en sus diversas caracterizaciones, fue penetrando y abriéndose hueco hasta adquirir mayor envergadura, esto es, hasta novelarse (Chevalier 1999; Muñoz Sánchez 2018; González Ramírez 2018). En el siglo siguiente, los autores iniciaron una labor de experimentación en el campo de la narrativa, ofreciendo como resultado modelos -algunos los han denominado manieristas- que se atenían al principio de la variedad. Además del diálogo, gozaron de apogeo las colecciones de facecias, los tratados de cortesanía, las misceláneas o la novela; pero el género de mayor éxito fue sin duda el refundado por Cervantes, que eclosionó en 1620.

En ese año el fenómeno de la novela corta alcanzó cotas inimaginables. Si Cervantes dio el pistoletazo de salida con sus Novelas ejemplares, en 1620 se dio una curiosa relación de prisas y prosas en la trayectoria de la novela corta. Cortés de Tolosa ( Laza-

9 Desde Platón, en su conocido diálogo convival El banquete, hasta escritores como Ateneo, Macrobio, Jenofonte o Plutarco, en la vertiente grecolatina, era frecuente emplear el marco de la sobremesa para encajar el diálogo. En la tradición humanística, Erasmo de Rotterdam, con su "Convite religioso", y Pedro Mejía, con sus "Coloquios del convite", quizá sean los exponentes más logrados de la influencia de este tipo de literatura simposíaca. Malpartida Tirado dedicó a los banquetes varias reflexiones en su monografía de 2005 (cf. pp. 171-177).

10 No puede olvidarse que traducciones como el Decameron de Boccaccio -cuya traducción castellana se mantuvo en la imprenta desde 1496 hasta 1550, última vez que fue reeditada-, las Piacevoli notti de Straparola -traducidas antes de 1578 y reeditadas hasta 1612- o los Hecatommithi de Cinthio -publicados en 1590- contenían marcos en los que un conjunto de personas (movido por diferentes razones) se reunía durante una época determinada y se entretenía contando cuentos.

11 Sobre el declive del diálogo durante el Barroco y la carencia de análisis críticos se ha extendido recientemente Gómez 2015. 
rillo de Manzanares con otras cinco novelas), Salas Barbadillo (Casa de placer honesto), Ágreda y Vargas (Novelas morales) y Liñán y Verdugo llevaron sus obras a las prensas de algún taller madrileño -la colección Teatro popular: novelas morales de Lugo y Dávila también había obtenido las licencias en 1620 , pero, por una serie de peripecias personales, la obra no se publicó hasta dos años después. A lo largo de esa década, Castillo Solórzano, Tirso de Molina, Montalbán, Piña y otros se unirán a la pléyade de novelistas que empezaron a cultivar un género que, con sus flujos y reflujos, no se agotó hasta las últimas décadas del siglo XVII ${ }^{12}$.

De estas colecciones, las de Salas, Liñán y Lugo se constituyeron como diálogos indirectos. De alguna manera, se estableció desde esta fecha una división entre las novelas sin marco y con marco $^{13}$. A propósito de estas colecciones enmarcadas, la corni$c e$ está constituida por una reunión, que puede tener un senti-

${ }^{12}$ Las recopilaciones de novelas cortas, concatenadas o con la inclusión de un marco que las englobase, se repitieron hasta la saciedad en la literatura española del Barroco. El auge de este tipo de obras, junto al consumo de un lectorado voraz, no tuvo parangón, si bien pocas de estas colectáneas tuvieron más de una tirada. La competencia y la proliferación de colecciones nuevas hacían que las ya publicadas se convirtiesen irremisiblemente para los editores en productos que pronto caían en el olvido. Muchos autores no dudaron en adaptarse a la moda literaria del momento y ponerse al servicio del potente público que se creó. Sobre el número de colecciones y reediciones, aún es preciso fijar una clasificación con criterios más fiables, porque los trabajos clásicos presentan deficiencias de diverso tipo. El de BourLand (1927) contiene, por ejemplo, obras como el Fabulario de Mey, que está lejos de poder considerarse una colección de novelas; el de Formichi (1976) adolece de varias imperfecciones, como no haber consultado algunas ediciones que citaba o registrar otras que eran noticias de oídas. Sobre estos dos catálogos formó su listado PaCHECo-RANSANZ (1986), quien se permitió matizar el catálogo de Formichi con criterios tan arbitrarios como excluir las Rimas y prosas de Bocángel, que contienen una novela, y admitir en cambio los Cigarrales de Tirso o La Filomena de Lope, que igualmente sólo albergan una pieza novelística.

${ }^{13}$ Cabe recordar que en la tradición italiana los autores ya habían fijado esta distinción y había convivencia entre las obras con marco y sin él. Dos de las más exitosas colecciones ya presentan esta diferencia; las Piacevoli notti (1551-1553) de Straparola, contadas durante unas carnestolendas por un grupo de narradores, se oponen a la yuxtaposición que presentan las Novelle (1566-1570) de Bandello en los cuatro volúmenes que publicó. La antología de mayor éxito en Italia, las Cento novelle scelte dai più nobili scrittori (1561) de Sansovino, también se presentó sin marco -como era de esperar, además, pues el editor escogió narraciones de libros diferentes y no aspiraba a fines literarios para concederles coherencia. Sobre el éxito en Italia de las colecciones sin cornice, véase el trabajo de BotTasso (1989). 
do celebrativo (unas carnestolendas, como en Carnestolendas en Madrid de Castillo Solórzano; una navidad, como en Navidades en Madrid, de Carvajal), solidario (para acompañar a alguien que está convaleciente, como en las Novelas de Zayas) o de entretenimiento (para divertirse durante las noches, como en Noches de placer de Castillo Solórzano) (Colón Calderón 2001, pp. 51-56).

Encontramos en este tipo de obras la idea de acudir a la palabra, a la ficción narrativa, para cubrir los momentos de ocio, que se entiende como un tipo de ocio intelectual, una palabra sabia que ayude a recrear el ánimo, en un sentido puramente eutrapélico. Hay por consiguiente una vinculación entre narración y entretenimiento/ aprovechamiento. La novela es la clave de bóveda de estas colecciones, pero en muchas de ellas el diálogo entre los contertulios es muy sustancioso y daría para preparar un estudio sobre la "civil conversación" en la novela corta del siglo xvir. Encontramos colecciones de novelas en las que el marco dialogal es mero soporte para embutir las piezas narrativas -o incluso las poéticas y/o dramáticas-, como es el caso de muchos libros de Castillo Solórzano (Tardes entretenidas, Sala de recreación, etc.). Además, el motivo del marco prácticamente nunca tiene incidencia sobre el tema que se trata en las novelas, como percibió Palomo $(1976)^{14}$. Sin embargo, en otros casos, el diálogo que se establece alcanza mayor complejidad estética y tiene un carácter más dinámico, al propiciar temas de discusión muy sugerentes en los cuales se intercalan opiniones sobre usos y costumbres, anécdotas, críticas sociales, cuentecillos, etcétera.

$\mathrm{Al}$ respecto, la conformación de la tertulia que aparece en la Guía se ordena, a modo de diálogo narrativo, siguiendo el modelo, por ejemplo, de El Scholástico de Villalón. Pero a diferencia de esta obra, o de El Cortesano de Castiglione en la tradición italiana (texto que imitó clarísimamente Villalón), Liñán logró amoldar al diálogo un género heredado de Boccaccio que

14 El poco interés que el enmarque tenía para CASTILlo se percibe claramente en sus dos primeras colecciones; cerró sus Tardes entretenidas (1625) anunciando que daba fin a su colección "por no hacer mayor volumen", y prometía "sacar a luz la segunda con mucha brevedad" (1992, p. 349). Al año siguiente publicó sus Jornadas alegres (1626), en cuyo prólogo recordaba que con esta nueva obra cumplía su promesa (1909, p. 10), y aunque respetó la idea del viaje de vuelta, los personajes no se corresponden, por lo cual, aunque se presenta como continuación, las Jornadas se pueden leer perfectamente como una obra independiente. 
empezó a descollar en España en las mismas fechas en las que se estaba componiendo la Guía y avisos de forasteros: la novela $\operatorname{corta}^{15}$. Su obra ofrece un ejemplo manifiesto de la pervivencia del diálogo en el siglo xviı y su fusión con la novela corta, que irrumpe en las primeras décadas. Liñán aprovechó el enmarque que le proporcionaba el Decameron y sus derivados, incluyó a cuatro interlocutores y dispuso un texto en el que hilvanó ocho avisos y catorce novelas.

Pero Liñán, que en cierta medida trabajó con los mismos temas y motivos que abundaban en la narrativa breve de su época, supeditó los amores furtivos, las infidelidades maritales, los castigos con venganzas y los desenlaces trágicos a un propósito común: avisar de los peligros de la corte. No sólo mezcló lo útil con lo dulce, como predicaban todos los autores de novelas cortas -siguiendo un topos de largo recorrido en la prosa narrativa-, sino que el diálogo le permitió originar un espacio en el que ofrecer una serie de recomendaciones positivas a los forasteros que acudían a la corte a pleitear o a pretender. El autor de estos desengaños cortesanos -perfectamente se podría haber titulado así su obra, en consonancia con los gustos de la época- no se apartó de la corriente en ebullición en los años veinte que iba a dominar la prosa novelística en la primera mitad del siglo XVII, pero tampoco renunció a adscribir su obra a un género de viejo cuño, el diálogo, que le brindaba una serie de posibilidades para dar mayor coherencia argumental a la colección.

Es interesante destacar, en este orden, que Liñán no quiso escribir un tratado o un discurso tout court sobre las recomendaciones que deben seguir los forasteros antes de adentrarse en la corte; tampoco fue su intención desarrollar un engranaje más de novelas cortas en las que en una reunión de relatores se contasen sucesos y casos para solazarse o distraerse durante un

${ }^{15}$ En El Scholástico o en El Cortesano encontramos debates sobre diferentes temas que se van proponiendo; el diálogo está salpimentado con una amplia tipología de narraciones breves (donaires, cuentecillos, etc.), pero ninguna alcanza la categoría de novela corta. En otros tratados de cortesanía posteriores, como la traducción libre de Il galateo de Della Casa, preparada por Gracián Dantisco con el título de El galateo español, donde incluyó de su magín la Novela del gran Soldán; o en Corte en aldea de Rodrigues Lobo, publicada en 1619 -y traducida al español en 1622-, en la que también se intercaló una novela corta que carece de final y que el lector puede seguir de forma discontinua. Véanse Gómez 2015 y González Ramírez 2020. 
período festivo o de convalecencia. Le interesaba, en consonancia con la moda literaria de su momento, seducir al lector con otro tipo de sales. De este modo, junto al didactismo que destila su obra, Liñán quiso entretener al lector; a este propósito, no es ocioso recordar el subtítulo de la obra: y, debajo de novelas morales y ejemplares escarmientos, se les avisa y advierte [a los forasteros] de cómo acudirán a sus negocios cuerdamente.

La fórmula de enseñar deleitando, conforme a la máxima horaciana fijada en la portada (Omne tulit punctum qui miscuit utile dulci), exigía que en la obra hubiese un equilibrado contrabalanceo de avisos (instrucciones) y escarmientos (novelas) ${ }^{16}$. Esta dicotomía del prodesse et delectare fue una finalidad por todos los escritores perseguida al trabajar en la novela corta del siglo XviI; Cervantes, en lo que él quiso dar a entender como un texto fundacional, desde su título aglutinó el deleite que producen las novelas con la enseñanza que se extrae de su ejemplaridad ${ }^{17}$. Como advirtió Sarrailh (1919 y 1921), Salas Barbadillo, en su Corrección de vicios (1615), ya había ofrecido un producto en el que se mixtificaban avisos y novelas, con procedimientos semejantes al que sólo unos años después pondría en práctica Lugo y Dávila en su Teatro popular (1622), según recordó también Fernández (1983, p. 176).

En las censuras y aprobaciones de los libros de la época (y de forma más preeminente en la novela corta) era común encontrar la sumaria fórmula que expresase el provecho y la utilidad del ejemplar que iba a ser mandado a la estampa. En este sentido, me parece destacable resaltar aquí el juicio de José Alonso Pinedo que se puede leer en la censura que entregó a mediados del siglo XviII; para Pinedo (1753, p. 3), quien leyese la obra de Liñán encontraría

16 No pasa desapercibido que el librero del siglo xvin, Alonso y Padilla, quisiese componer dos obras separadas de la que originalmente publicó Liñán y Verdugo: Novelas morales y ejemplares y Aviso de forasteros en la corte de Madrid, en varias novelas, lo que pasa en la corte y las posadas. Ambas entradas aparecen con los registros 24 y 29 en el proyecto editorial (frustrado en gran parte) que este librero adjuntó a algunos de sus libros publicados. Véase RiPOll y DE LA Flor 1991, quienes reeditaron este catálogo.

17 Recuérdese, por ejemplo, lo que SuÁrez de Figueroa comentaba sobre las particularidades de las novelas por medio de uno de los dialogantes de El pasajero (1617): "tomadas con el rigor que se debe, es una composición ingeniosísima, cuyo ejemplo obliga a imitación o escarmiento" (1988, p. 179). 
diversión, desengaño y reglas prudentes en que poderse gobernar entre los muchos lazos que se suelen encontrar en el mundo abreviado de esta corte. Cada novela o parábola es un farol encendido que sirve de gobierno a quien quiera enderezar sus pasos: está escrito no sólo con sal, sino con un género de dulzura que fastidia menos cuanto más se lee; y aunque su intento es guiar forasteros y novicios en este cortesano laberinto, su eficacia alcanza a desengañar aun a los veteranos.

Es evidente que en la composición de su obra, Liñán mostró tener plena conciencia de su interés por situarse en una zona fronteriza entre el diálogo y la narración. Con respecto al primer componente, la Guía y avisos de forasteros pone de relieve que algunos principios compositivos del diálogo -como la caracterización de los personajes, la recreación conversacional o los recursos de activación y progresión de la plática- podían aportar a la novela corta un excelente encuadre para enriquecer la propia narración -el hecho, sobre el que más adelante me detendré, de que varios de los dialogantes conozcan algunos de los casos que se refieren propicia que se maticen o amplíen datos de los propios relatos-, para potenciar la verosimilitud de los casos contados - pues en ocasiones se aportan como ejemplos sucesos que les han acaecido a los propios dialoganteso incluso para imprimir a la propia composición una unidad que se acercase de forma más cálida -y no de forma tan lineal y mecanicista como en la mayoría de las colecciones de novelas del siglo XVII- a la configuración literaria de una congregación de personas que se disponen a relatar cuentos y novelas ${ }^{18}$.

Los diálogos principalmente encuentran su espacio de desarrollo en los avisos incorporados, que se atienen a un manifiesto fin didáctico, pues se deja meridianamente claro una y otra vez que la intención es la de poner sobre aviso a los foráneos que lleguen al gran piélago que simboliza Madrid. Los avisos que recomienda seguir el Maestro pueden venir ilustrados hasta con tres "escarmientos" (las narraciones, a excepción del que cierra la obra, que no contiene ninguno, sólo la doctrina y un emplazamiento para una futura reunión), aunque en la

18 En las siguientes páginas veremos cómo Liñán alcanzó efectos muy interesantes para estudiar esta fórmula que mixtificaba diálogo y novela. Sin embargo, no es ocioso que se precise que en determinados momentos no mostró demasiado interés por detallar aspectos tan sugerentes de la recreación conversacional como el espacio y el tiempo. 
mayoría de los casos no alcanzan la categoría de novela ${ }^{19}$. En los primeros se da a los forasteros una serie de consejos para que presten atención al lugar en el que toman su posada, en quién deben admitir en su compañía, en qué entretenimientos es recomendable que se ocupen o en cómo es más provechoso repartir el tiempo libre ${ }^{20}$. Los escarmientos, así como los cuentecillos y facecias que se incluyen en los avisos -y aun al final de las narraciones-, ilustran los desengaños a los que llegan los forasteros que se han distraído con las veleidades de la corte o que se han dejado engañar incautamente.

\section{Elementos diAlogales EN LA GUÍA Y AVISOS DE FORASTEROS}

En este sentido, habría que precisar que la Guía y avisos de forasteros no es ni más ni menos que una colección de relatos enmarcados en una tertulia en la que participan cuatro dialogantes. Por tanto, es imprescindible analizar con cierto pormenor los mecanismos que favorecen la mimesis conversacionaly potencian la cohesión compositiva de la obra ${ }^{21}$. En tal orden, es importante observar cuál es el resorte dialogal que genera el coloquio y su desarrollo. La obra se abre con una "introducción" a modo de marco -cumpliendo exactamente la misma función que en $\mathrm{El}$ pasajero de Suárez de Figueroa, en Casa del placer honesto de Salas

19 Sobre el asunto ya se extendió Fernández (1983). En rigor, novela corta, según fue entendido el género después de ser refundado por Cervantes, sólo es la primera; las demás narraciones, incluidas muchas de las que forman parte del marco conversacional, caen en la categoría de cuentos o facecias, pues tienen un desarrollo argumental mucho más sencillo, se quedan a menudo en la anécdota y en numerosos casos apenas superan las dos o tres páginas.

20 Ofrezco aquí el listado completo de los temas que tratan los avisos que se brinda al forastero: 1) sobre "el peligro que corre en el tomar posada en ruin vecindad"; 2) sobre "qué amigos elige"; 3) "Por qué calles pasea"; 4) "En qué manos da y en qué manera de hombres pone la solicitud de sus negocios"; 5) que "huya de los entretenimientos vanos y ocupe el tiempo en sus negocios; 6) que "se guarde y huya de otra manera y suerte de hombres que de ordinario andan en la Corte"; 7) "Cómo se ha de haber" "en la Corte" "si fuere mozo y quisiere tomar estado", "y si fuere casado y trajere consigo hijos, cómo los ha de criar y enseñar para que no se le pierdan”; 8) "cómo ha de repartir el tiempo y acudir a sus ocupaciones cristianamente".

${ }^{21}$ Para el valor de este concepto, es indispensable tener en cuenta los trabajos fundacionales de Vian Herrero (1987 y 1988); en el primero de ellos lo aplica muy inteligentemente al Diálogo de la lengua de Juan de Valdés. 
Barbadillo o en Teatro popular de Lugo y Dávila- donde el narrador, en un sencillo párrafo, presenta una situación encontradiza en la que dos cortesanos antiguos ("un maestro graduado en Artes y Teología y un cortesano antiguo llamado don Antonio, dado también a las letras humanas; el uno pleiteante y el otro pretendiente", Liñán 2011 [1620], p. 165) se encuentran en el patio de Palacio con un viejo amigo de Granada, que acaba de llegar a la corte para resolver unos pleitos ${ }^{22}$. La caracterización del Maestro y de don Antonio se aclimata perfectamente a las exigencias de la obra; pleiteante y pretendiente, ambos cortesanos antiguos, son los que asumen el papel principal de avisar a don Diego de los riesgos de la corte. Nadie más experimentado que ellos en las lides cortesanas para dar consejos a los futuros allegados que quisieran aventurarse en el maremágnum cortesano durante el reinado de Felipe III.

Tras este breve incipit o praeparatio característico del género dialogal, la conversación se inicia entre los tres personajes que aparecen; el enmarque cumple en la obra una mera función de presentación contextual para introducir a los personajes. A partir de este momento, el lector queda ubicado en el escenario donde va a tener lugar la congregación de los dialogantes que intervendrán; en adelante, serán estos últimos los que cobren protagonismo, pues la voz extradiegética no volverá a resurgir en el texto: su función quedará reducida a esta breve descripción inaugural del encuentro entre tres de los contertulios. El resto de la obra pasa a configurarse como un diálogo indirecto entre los personajes. Es en esta cornice, precedente del aviso primero, donde se manifiesta la intención del texto, ayudada por la petición que hace el forastero al Maestro de que le acomode en una buena posada,

o en parte que esté con la disposición y quietud que pide la asistencia de un hombre mozo como yo, que viene a estar de espacio en esta Corte, de quien los dos, por la comunicación y amistad que habéis tenido conmigo, sabéis cuán fácil soy en dejarme llevar de las ocasiones con quien encuentro, y que mi natural se parece al vidrio o a cualquiera otro cuerpo diáfano,

${ }^{22}$ Frente al recurso del coloquio pactado, el encuentro fortuito aparece en obras tan señeras del diálogo renacentista como los Diálogos de Pedro Mejía, los Coloquios satíricos de Antonio de Torquemada, el Diálogo de Lactancio y un arcediano de Alfonso de Valdés o el Viaje de Turquía. 
que al color que le ajuntan, de aquel se muestra y parece (Liñán 2011 [1620], p. 167).

La condición maleable de don Diego hay que interpretarla como el catalizador de la obra, pues a partir de esta confesión don Antonio interviene para indicar que el Maestro, conforme a lo prometido, debe presentar "unas reglas y avisos para enseñar a los forasteros recién venidos a esta corte, ora sea a pretender, ora a pleitear, cómo han de vivir y de qué modo se han de haber en ella para huir los grandes y diversos peligros suyos para quien no tiene experiencia y práctica" (id.).

De la caracterización de don Diego como "mozo" pueden inferirse algunas de las cualidades de su carácter dúctil y acomodaticio. Sus intervenciones siempre están encaminadas a mostrar sus aficiones y preferencias, las cuales sirven de correa de transmisión del diálogo, pues generalmente sus inclinaciones son ejemplos reprobatorios que valen para relatar aquellos desengaños que personalidades como la suya pueden sufrir. Él mismo se preocupa por pedirle a sus amigos que no se distraigan del propósito que han emprendido; a tal respecto, cuando están tratando sobre las estafas que maquinan los "capigorras" o estudiantes falsos, don Diego hace una aclaración que incide en la importancia de estas lecciones para su formación en la corte de los engaños:

Acerca de los daños que hacen con fingirse astrólogos y matemáticos, quirománticos, adivinadores o, por mejor decir, embusteros, podrá ser que de ahí salga algún ejemplar escarmiento como yo le he menester, porque soy tentado por saber cosas nuevas, y si no me espantáis las orejas con algo que me haga asombro, me sirva de freno, podrá ser que me pierda por ahí más que por otra parte, porque soy amicísimo de saber (p. 259).

En otro lugar, es don Diego quien manifiesta su incertidumbre sobre cómo ocupar el tiempo libre, poniendo en la conversación un tema sobre el que al autor le interesaba sermonear: "Mozo soy, y las horas que me sobraren de mis ocupaciones precisas no sé cómo las ocuparé. Soy inclinado a oír comedias. ¿Qué sentistes de las comedias?” (p. 243). Don Diego no sólo cumple el papel del discípulo dócil que atiende sumisamente al Maestro y que se muestra incapacitado para plantear sus dudas; en este caso, el dialogante da pie al Maestro para que agregue 
algún aviso más a los que tiene preparados de antemano. Es una fórmula que sirve a Liñán y Verdugo para ampliar el diálogo, para dinamizarlo, y evitar así que el desarrollo de la enseñanza se convierta en un proceso mecanizado y austero.

La instrucción no surge únicamente de las lecciones previstas por el Maestro, sino que también responde a las inquietudes del discípulo. El recurso puesto de relieve es nuevamente empleado en otro lugar; en esta ocasión, don Diego se interesa por los riesgos que puede conllevar desposarse en la corte, así como el peligro que habría en colocar a sus hermanos en alguna familia distinguida:

Por cierto, señor Maestro, que no sólo estoy escarmentado con los casos oídos, pero me he acobardado notablemente para emprender algunas cosas que traía en mi ánimo de ejecutar en esta Corte con licencia de mis padres. La una era, ofreciéndose ocasión tal, casarme y tomar estado; y la otra, dos hermanos pequeños que tengo en edad tierna, ponerlos aquí en servicio de alguna persona poderosa, porque salieran de la miseria y cortedad de aquella tierra y se criaran en esta Corte, que como dicen, en el gran mar se cría el gran pez (Liñán 2011 [1620], p. 281).

Al final, don Diego reconoce el magisterio de los cortesanos antiguos que le han ofrecido el cuaderno de bitácora para sortear los peligros de la gran urbe: "voy tan advertido y consolado con los avisos y ejemplos referidos que me prometo en mis negocios bonísimos sucesos" (p. 310); su última duda ("sólo lo que tengo que replicaros es: aconsejastes al forastero, en saliendo de casa a negociar, lo primero que hiciese fuese oír misa. Querría que no estuviese lejos mi posada de la iglesia") sirve para que el Maestro, como colofón, realice "una división de Madrid o descripción, no en rigor cosmográfico, sino por mayor" ( $i d$.$) . Como otro tipo de obras que pertenecen o están$ en los aledaños de la novela corta del siglo XVII, también la Guía y avisos de forasteros termina con un final abierto que deja la posibilidad de una futura continuación. Es el Maestro quien se ofrece para hacer,

la primera vez que nos volviéremos a juntar, ...una descripción cosmográfica del sitio y población de Madrid, de su latitud y longitud, de la tierra en que está, del clima que goza, de los aires que la bañan, del número de sus casas y vecinos, poniendo cada cosa en su lugar, y no faltarán otros avisos que dar al forastero. Ahora 
me habréis de perdonar, porque me llama la cena y me esperan los amigos (p. 312).

Por otra parte, la obra se configura, en la tipología establecida (que aglutina los diálogos catequísticos, polémicos, misceláneos y narrativos) ${ }^{23}$, como un diálogo catequístico, es decir, aquel que trata de instruir utilizando el método de plantear preguntas y respuestas. Malpartida Tirado (2005, pp. 18-19) considera que hay que afinar y establecer distintos grados de adscripción, pero

a simple vista responden a una mayor desnudez en lo que atañe a recreación conversacional y delineación de los interlocutores y del marco espacio-temporal, además de que aparentemente discurren más por una vía monológica que los emparenta con el tratado, de manera que las intervenciones de los domandatoriapenas si se distinguen de los epígrafes que podrían haber figurado en una obra no dialogada.

Es conveniente anotar, por tanto, que en la Guía se aprovechan ágilmente algunos de los recursos generales que proporciona el diálogo, y en particular se saca partido de las técnicas que facilita la utilización del modelo catequístico. En la Guía funciona perfectamente la dinamización dialogal que da sentido al proceso de enseñanza-aprendizaje, pues aunque en el texto se indica que el Maestro y sus dos contertulios cortesanos (don Antonio y Leonardo) ya habían acordado "la noche pasada” (p. 167) fijar un día para ofrecer las reglas y avisos, la llegada a la corte de don Diego propicia que entre la condición de los dialogantes y el tema sobre el que se va a tratar haya íntegra cohesión. Malpartida (2008, p. 124) explicó que "en la Atenas del siglo v a. de C., hay un maestro por encima de todos. En el Renacimiento, hay maestros, sobre todo en los diálogos de corte pedagógico”. En este sentido, la Guía y avisos de forasteros, con un claro significado didáctico, se somete perfectamente a esta pluralidad de dómines; el desnivel de conocimientos genera un contexto de enseñanza-aprendizaje idóneo, con el Maestro cumpliendo la función de persona capacitada para

${ }^{23}$ Prieto (1986, pp. 99-114) estudió las distintas divisiones taxonómicas que establecieron los teorizadores del diálogo en el siglo xvi. Sobre esta denominación, véanse los estudios de conjunto de Gómez (1988) y FERRERAS (2003). 
ofrecer avisos a los forasteros -ayudado por sus dos convecinos, que también relatan casos para escarmiento del recién llegado-, y don Diego como aprendiz o domandatore.

Otro punto que se debe tener en cuenta es que, a diferencia de las novelas que pueden leerse en las colecciones enmarcadas-cuyas narraciones se cuentan sin interrupciones que generen una cesura-, las que se publicaron en la obra de Liñán aparecen generalmente con rupturas que provocan los oyentes en el curso del relato -recurso, por cierto, que ya estaba en el Decameron. Es necesario advertir que muchos de los autores del siglo Xvi que empleaban la estructura dialogal para vertebrar sus obras no cultivaban las posibilidades que les ofrecía el género con el que estaban trabajando. Liñán, aunque sea parco al referir aspectos sobre el espacio o el tiempo, se preocupó por aprovechar otros recursos que le facilitaba el diálogo. Fácil de hallar en la Guía y avisos de forasteros, por la multitud de casos que suscita, es el de la narración interrumpida por uno de los oyentes para aclarar algún punto oscuro. Un ejemplo de este recurso se genera cuando Leonardo, en un momento determinado, suspende el curso de la narración para poner en claro una duda que le asalta: "-Perdonadme -dijo Leonardo- que me habéis de dar licencia para reparar en una dificultad que se me ofrece. Supuesto, como vos acabáis de decir, que Feliciano habló claro a doña Brianda, ¿cómo se atrevió a fiar la comunicación de doña Juana con él?" (p. 184). O asimismo, en otro lugar, es don Antonio quien tiene una curiosidad que no puede reprimir: "¡Por vida de Leonardo! -dijo don Antonio-, que me digáis, que he deseado preguntároslo, ¿no reparaban esas señoras con quien ya tenía cabida, en que era mal nombre el de doña Pestaña?" (p. 237).

Los dialogantes, con estas irrupciones, expresan las dudas que en ese momento puede tener un lector u oidor. La novela, al igual que los avisos del Maestro, no se configura como un relato cerrado, sino que queda supeditada a las preguntas y sugerencias de los dialogantes. En el escarmiento octavo, por ejemplo, se produce una interrupción para aclarar un punto sobre las mohatras, y su narrador, Leonardo, ante la petición de que prosiguiese "su cuento", se lamenta porque "lo que queda por referir... es tan malo que más valiera dejarlo aquí". El Maestro, que sabe "el fin que tuvo y me duele harto el acordarme dél", le replica de forma categórica que todo "se cuenta... para escarmiento de don Diego y de los demás negociantes y plei- 
teantes" (p. 251). Si las cuestiones planteadas por don Diego eran parte constituyente de los avisos, los demás dialogantes -en calidad de oidores- han de considerarse elementos que condicionan la narración, al participar de forma activa en muchos momentos del desarrollo argumental de las novelas.

Como ya he anotado, el diálogo que se origina en la obra de Liñán no se beneficia de elementos tan sugerentes para la recreación conversacional como el espacio y el tiempo. Sobre el lugar, en el marco inaugural se nos indica que saliendo de "Palacio" se produjo el encuentro del Maestro y don Antonio con el recién llegado, don Diego (p. 165); pero nada sabemos sobre hospedaje y el lugar donde se da la plática. Únicamente, don Antonio, aludiendo a los avisos que les había prometido el Maestro, refiere que los tres posan juntos. Con la incorporación a la tertulia del cuarto dialogante, Leonardo ("el cual, por haber sido convidado de otros amigos aquel día, no se había hallado al buen acogimiento que se le había hecho a don Diego"), se refuerza la idea, pues el narrador apunta que "era el otro amigo que se hospedaba... con el Maestro y con don Antonio" (p. 173).

En cuanto al tiempo, por las referencias que se nos aportan, el encuentro debió de ocurrir justo antes de mediodía, pues el forastero es invitado "a comer" (p. 167) ${ }^{24}$. Las únicas referencias al tiempo interno aparecen solamente al inicio y al final del diálogo; éste se ve favorecido, en primera instancia, por el encuentro fortuito y por la petición de don Diego de que le aconsejen sobre dónde tomar posada; y después, porque el tema se ajustaba a lo que habían propuesto "la noche pasada". Acuerdan verse a mediodía para almorzar y tratar luego sobre los consejos a los forasteros, pues si los "nublados" no invitan a dormir la "siesta” (p. 167), conceden en cambio unas horas para la reunión entre amigos. Al final, tópicamente, la conversación se cierra porque "anochece", y el Maestro, declara, ha sido "convidado a cenar" (p. 305) 25

${ }^{24}$ A la comida que han tomado también se refieren escuetamente al inicio de la plática el Maestro y don Diego (p. 169).

25 Se trata de uno de los recursos habituales utilizados en el diálogo para interrumpir la plática; se puede ver también en la obra de Alcalá Yáñez, Alonso, mozo de muchos amos (1624-1626) -para el propósito de este procedimiento, cf. GonzÁlez Ramírez 2015. Es importante indicar, como ya hizo FERNÁNDEZ (1983, p. 178), que el tiempo se limita a una tarde, por lo que se da un efecto isocrónico con respecto a la lectura completa del libro. Este 
Por todo lo explicado líneas arriba, creo conveniente excluir la Guía y avisos de forasteros de esa zona limítrofe que la sitúa en los aledaños de la novela picaresca: ni por la forma ni por el fondo puede hallarse ésta en los paraderos del cuadro que componen obras como el Lazarillo, el Guzmán o el Buscón. La colección de Liñán trata sobre los bajos fondos de la sociedad matritense, por lo que la presencia de timadores y busconas es consustancial al propósito de enmienda que plantea el texto. En este sentido, está muy cerca ideológicamente de otras colecciones como Corrección de vicios de Salas Barbadillo, en la que también se relatan novelas protagonizadas por pícaras, embusteros y gorrones (y sin embargo no ha sido relacionada con el género picaresco). Un caso bien distinto es el de Las harpias en Madrid de Castillo Solórzano, que sí forma parte de la fusión entre novela corta y picaresca (como estudió Velasco Kindelán 1983), pues las narradoras del marco son estafadoras y quienes protagonizan las cuatro novelas intercaladas.

El hecho de que trate sobre Madrid exclusivamente tampoco significa per se que podamos adscribir la Guía al costumbrismo; podría admitirse que indirectamente sirvió de acicate para la formación de ese nuevo género, pero desde el texto de Liñán hasta el de Remiro de Navarra transcurrió un cuarto de siglo, medió Las harpías en Madrid (clave en la evolución narrativa) y hay una distancia compositiva de gran calado: ausencia del marco (y por tanto de los narradores y del diálogo), fijación por la codicia femenina, descripción de varios escenarios de la corte (como el Prado, el Soto o la calle Mayor), etc. El género del libro compuesto por Liñán, por tanto, hay que retrazarlo desde el hibridismo que recorre casi toda la narrativa del siglo XVII, pero por otros contornos, indudablemente.

La Guía y avisos de forasteros es un ejemplo más de colección de novelas, aunque con sus peculiaridades. De entrada, el concepto de novela que maneja el autor (y que figura en los epígrafes: "novela y escarmiento") tiene bastante amplitud, pues la mayoría no alcanza esta categorización, y más bien se adap-

efecto de isocronía entre el tiempo de la enunciación y del enunciado, en términos narratológicos, se produce también en otros diálogos de la época, como por ejemplo en el "Coloquio de la desorden del comer y beber" de Torquemada (incluido en sus Coloquios satíricos, 1553). 
ta a la forma de cuentos o anécdotas; de hecho, en cuanto a su desarrollo, hay narraciones en el marco ("aviso") o en la parte final de cada "novela", cuando los dialogantes reanudan el coloquio, más extensas y de mayor elaboración que la que constituye el escarmiento. El texto de Liñán nos da pistas muy interesantes sobre la indefinición que a inicios del siglo XviI se tenía sobre el término novela, que había fluctuado desde finales de la Edad Media, cuando se comenzó a utilizar, con el de cuento; resulta muy sintomático que el propio Cervantes, que tituló en 1613 su colección Novelas ejemplares (y en el prólogo, al hablar sobre las "novelas", se ufanase de ser el "primero en novelar en lengua castellana"), aludiese a los "doce cuentos" en su dedicatoria a don Pedro Fernández de Castro (2001 [1613], p. 18) ${ }^{26}$.

Por lo demás, los cuatro narradores que intervienen en el marco del libro de Liñán actúan con una libertad dialógica impropia de las colecciones de novelas, en que el encuadre sirve más bien para dar cobertura a las novelas, que es donde los autores ponían su maestría narrativa en juego. En el siglo XVII el diálogo fue menos cultivado que en el Quinientos, pero los ejemplos con los que contamos han de estudiarse en profundidad para valorar cómo interactúan los personajes y cómo funciona la recreación dialogal. En este orden, la Guía y avisos de forasteros delata su herencia de los diálogos del siglo anterior y permite estudiarla desde sus mismos principios; en aquellos casos generalmente era una materia (la comida, la indumentaria, los viajes, las enfermedades, etc.) la que ordenaba el coloquio; en la obra de Liñán, cada aviso está orientado por una recomendación al forastero, que en su conjunto forma un manual para sortear los peligros de la corte. A propósito de esta organización reglada de las materias, no cabe, por último, endosarle el término miscelánea, porque además en la Guía no hay vulgarización de saberes enciclopédicos; al contrario, todo está dirigido a enseñar a los forasteros a no dejarse embaucar por la turbamulta de fulleros que hay en la corte. Parece claro que Liñán utilizó, con una conciencia y pragmatismo que hasta ahora se le han negado, el molde dialogal para configurar una obra que se ubica en una zona equidistante entre la colección enmarcada de novelas cortas y el diálogo renacentista.

${ }^{26}$ Sobre el concepto de novela en el Siglo de Oro, véase el panorama presentado en GonZález RAmírez 2013. 


\section{REFERENCIAS}

Arredondo Sirodey, María Soledad 2001. "De la picaresca menor al «costumbrismo»: la Guía y avisos de forasteros... y otros escarmientos", Edad de Oro, 20, pp. 9-21; doi: 10.15366/edadoro2001.20.

Arredondo Sirodey, María Soledad 2004. "El engaño cortesano en los relatos de la Guía y avisos de forasteros que vienen a la corte, de Liñán y Verdugo", en Siglos dorados. Homenaje a Augustin Redondo. Coord. Pierre Civil, Castalia, Madrid, t. 1, pp. 67-82.

Arredondo Sirodey, María Soledad 2009. "«A todos y a todas»: cuestiones de «género» en la prosa del siglo Xviı hasta El hombre práctico (1686)", Criticón, 105, pp. 177-198; doi: 10.4000/criticon.12962.

Auladell Pérez, Miguel Ángel 1991. La "Guía y avisos de forasteros que vienen a la corte" del Licenciado don Antonio Liñán y Verdugo en su contexto literario, Universidad de Alicante, Alicante. [Memoria de licenciatura: 2 microfichas].

Bobes Naves, María del Carmen 1992. El diálogo, Gredos, Madrid.

Bottasso, Enzo 1989. "La prima circolazione a stampa", en La novella italiana. Atti del Convegno di Caprarola, 19-24 settembre, 1988. Ed. Stefano Bianchi, Salerno Editrice, Roma, t. 1, pp. 245-264.

Bourland, Caroline B. 1927. The short story in Spain in the Seventeenth Century, Smith College, Northampton.

Bradbury, Jonathan 2014. "La narrativa breve en la miscelánea del siglo xviI", Edad de Oro, 33, pp. 211-224; doi: 10.15366/edadoro2014.33.013.

Bradbury, Jonathan 2017. The miscellany of the Spanish Golden Age. A literature of fragments, Routledge, Abingdon.

Castillo Solórzano, Alonso de 1909 [1626]. Jornadas alegres. Ed. Emilio Cotarelo y Mori, Librería de los Bibliófilos Españoles, Madrid.

Castillo Solórzano, Alonso de 1992 [1625]. Tardes entretenidas. Ed. Patrizia Campana, Montesinos, Barcelona.

Cervantes, Miguel de 2001 [1613]. Novelas ejemplares. Ed. Jorge García López, Crítica, Barcelona.

Chevalier, Maxime 1999. "Prólogo", en Cuento y novela corta en España. T. 1: Edad Media. Ed. María Jesús Lacarra, Crítica, Barcelona, pp. 9-24.

Colón Calderón, Isabel 2001. La novela corta en el siglo XVII, Laberinto, Madrid.

Correa Calderón, Evaristo 1949. "Iniciación y desarrollo del costumbrismo en los siglos XVII y xviII”, Boletín de la Real Academia Española, 28/29, 127, pp. 307-324.

Correa Calderón, Evaristo 1964. "Introducción al estudio del costumbrismo español”, en Costumbristas españoles, $2^{\mathrm{a}} \mathrm{ed}$. Ed. Evaristo Correa Calderón, Aguilar, Madrid, pp. xi-cxl.

FERnÁndez, ÁnGEL-RAIMUndo 1983. "Novela corta marginada del siglo XVII. Notas sobre la Guía y avisos de forasteros y El filósofo del aldea”, en Homenaje a José Manuel Blecua. Gredos, Madrid, pp. 175-192.

Fernández Nieto, Manuel 1973. "Nuevos datos sobre autores de novela cortesana”, Revista de Archivos, Bibliotecas y Museos, 76, pp. 423-437. 
Fernández Nieto, Manuel 2013. "Entre costumbrismo y novela. Antonio Liñán y Verdugo y Baltasar Mateo Velázquez”, Mélanges de la Casa de Velázquez, 43, 2, pp. 53-67; doi: 10.4000/mcv.5139.

FerReRAs, JaCQUELINe 2003. Los diálogos humanísticos del siglo XVI en lengua castellana, Universidad de Murcia, Murcia.

Formichi, Giovanna 1976. "Bibliografia della novella seicentesca”, Lavoce Ispanistici, 3, pp. 5-105.

Gili Gaya, SAmuel 1953. "Apogeo y desintegración de la novela picaresca”, en Historia general de las literaturas hispánicas. T. 3: Renacimiento y Barroco. Dir. Guillermo Díaz-Plaja, Vergara, Barcelona, pp. i-xxv.

Gómez, Jesús 1988. El diálogo en el Renacimiento español, Cátedra, Madrid.

Gómez, Jesús 2015. Tendencias del diálogo barroco. (Literatura y pensamiento durante la segunda mitad del siglo XVII), Visor, Madrid.

GonzÁlez de Amezúa y Mayo, Agustín 1951 [1929]. "Formación y elementos de la «novela cortesana»", en Opúsculos histórico-literarios, CSIC, Madrid, t. 1, pp. 194-279.

GonzÁlez Ramírez, DAVID 2010. "La disolución del marco narrativo en el origen del costumbrismo. De la Guía y avisos de forasteros a los días de fiesta de Zabaleta", Cuadernos de Filología Italiana (volumen extraordinario: Relecturas de Boccaccio: narrativa de los Siglos de Oro, cine y teatro. Eds. María Hernández, Marcial Carrascosa y Mita Valvassori), 5/6, pp. 81-94.

GonzÁlez Ramírez, David 2010a. "Rémoras y vagabundos en el Madrid de los Austrias. El mensaje contra la ociosidad de la Guía y avisos de forasteros (1620) entre los arbitrios de la época”, Dicenda, 28, pp. 57-72.

GonzÁlez Ramírez, David 2013. "Del término al género. El rastro de la «novela» desde Boccaccio hasta Cervantes", en Estelas del "Decamerón" en Cervantes y la literatura del Siglo de Oro. Coords. Isabel Colón Calderón y David González Ramírez, Universidad de Málaga, Málaga, pp. 123-144. (Anejos de Analecta Malacitana, 95).

GonzÁlez Ramírez, David 2015. "Nouvelle et dialogue au Xvir siècle en Espagne: autour de la picaresque", en Les états du dialogue à l'âge de l'Humanisme. Dirs. Emmanuel Buron, Philippe Guérin et Claire Lesage, Presses Universitaires François-Rabelais-Presses Universitaires de Rennes, Rennes, pp. 195-207.

GonzÁlez RAmírez, DAvid 2018. "Breve geografía del cuento en el siglo XVI: la invención de la novela corta", eHumanista. Journal of Iberian Studies (número monográfico: "Compuestas fábulas, artificiosas mentiras”. La novela corta del Siglo de Oro. Eds. David González Ramírez y María Ángeles González Luque), 38, pp. iii-xxiv.

GonzÁlez Ramírez, DAvid 2020. "Literatura cortesana y narrativa en el Siglo de Oro. De Castiglione a Salas Barbadillo", en La narrativa de Alonso Jerónimo de Salas Barbadillo. Coords. Mechthild Albert, Victoria Aranda y Leonardo Coppola, Peter Lang, Frankfurt/M., pp. 15-41.

Joset, Jacques 1977. “Introducción”, en Agustín de Rojas, El viaje entretenido, Espasa-Calpe, Madrid, t. 1, pp. vii-lxiii.

LiÑán y Verdugo, Antonio 1620. Guía y avisos de forasteros, adonde se les ensena a huir de los peligros que hay en la vida de corte y, debajo de novelas morales y ejemplares escarmientos, se les avisa y advierte de cómo acudirán a sus negocios cuerdamente, viuda de Alonso Martín, Madrid. 
LiñÁn y Verdugo, Antonio 1753. Guía y avisos de forasteros que vienen a la corte. Historia de mucha diversión, gusto y apacible entretenimiento, donde verán lo que les sucedió a unos recién venidos; se les enseña a huir de los peligros que hay en la Corte y, debajo de novelas morales y ejemplares escarmientos, se les avisa y advierte de cómo acudirán a sus negocios cuerdamente. Su autor el Licenciado don Antonio Liñán y Verdugo, Francisco Javier García, Madrid.

Liñán y Verdugo, Antonio 2011 [1620]. Guía y avisos de forasteros, en David González Ramírez, Del taller de imprenta al texto crítico. Recepción y edición de la "Guía y avisos de forasteros" de Liñán y Verdugo, Universidad de Málaga, Málaga. (Anejos de Analecta Malacitana, 79).

Malpartida Tirado, Rafael 2005. Varia lección de plática áurea. Un estudio sobre el diálogo renacentista español, Universidad de Málaga, Málaga. (Anejos de Analecta Malacitana, 54).

Malpartida Tirado, Rafael 2007. "Deslindes de la miscelánea en el Renacimiento español”, Epos, 23, pp. 41-60; doi: 10.5944/epos.23.2007.10543.

Malpartida Tirado, Rafael 2008. "Encantamientos del diálogo humanístico: la memoria y el olvido", Dicenda, 26, pp. 117-136.

Maravall, José Antonio 1986. "La crítica de la ociosidad en la época del primer capitalismo", en Homenaje a Pedro Sáinz Rodríguez. T. 4: Estudios teológicos, filosóficos y socioeconómicos, Fundación Universitaria Española, Madrid, pp. 521-538.

Muñoz SÁnchez, JuAn RAmón 2018. “"Desvarío laborioso y empobrecedor el de explayar en quinientas páginas una idea cuya perfecta exposición oral cabe en pocos minutos»: cuento y novela corta en España en el siglo XvI", eHumanista (número monográfico: "Compuestas fábulas, artificiosas mentiras”. La novela corta del Siglo de Oro. Eds. D. González Ramírez y M. Ángeles González Luque), 38, pp. 252-295.

Pacheco-Ransanz, Arsenio 1986. "Varia fortuna de la novela corta en el siglo Xviı", Revista Canadiense de Estudios Hispánicos, 10, 3, pp. 407-421.

Palomo, María del Pilar 1976. La novela cortesana: forma y estructura, Planeta-Universidad de Málaga, Madrid.

Prieto, Antonio 1986. La prosa española del siglo XVI, Cátedra, Madrid.

Rioja Murga, Antonio José 1993. "Sobre Los peligros de Madrid de Baptista Remiro de Navarra (1646)", Angélica, 5, pp. 135-144.

Ripoll, Begoña y Fernando R. De la Flor 1991. "Los cien Libros de novelas, cuentos, historias y casos trágicos de Pedro Joseph Alonso y Padilla", Criticón, 51, pp. 75-97.

Ruiz Pérez, Pedro 2008. "Venteando la novela", en La tropelía. Hacia el "Coloquio de los perros". Ed. Julián Jiménez Heffernan, Artemisa, Tenerife, pp. 379-429.

Sánchez Alonso, Benito 1925. "Los avisos de forasteros en la corte", Revista de Bibliotecas, Archivos y Museos, 7, pp. 325-336.

SARRAilh, Jean 1919. "Algunos datos acerca de D. Antonio Liñán y Verdugo, autor de la Guía y avisos de forasteros (1620)", Revista de Filología Española, 6, pp. 346-363.

SARRAilh, JeAn 1921. "Algunos datos acerca de D. Antonio Liñán y Verdugo, autor de la Guía y avisos de forasteros (1620). II", Revista de Filología Española, 7, pp. 150-160. 
Suárez de Figueroa, Cristóbal 1988 [1617]. El pasajero. Ed. María Isabel López Bascuñana, PPU, Barcelona.

Velasco Kindelán, Magdalena 1983. La novela cortesana y picaresca de Castillo Solórzano, Institución Cultural Simancas, Valladolid.

Velázquez, Baltasar Mateo 2019 [1625]. El filósofo del aldea. Ed. Jonathan Bradbury, Sial, Madrid. (Serie: Prosa Barroca, 12).

Vian Herrero, Ana 1987. "La mímesis conversacional en el Diálogo de la Lengua de Juan de Valdés", Criticón, 40, pp. 57-71.

Vian Herrero, Ana 1988. "La ficción conversacional en el diálogo renacentista”, Edad de Oro, 7, pp. 173-188. 
